\title{
Factors that promote HIV disclosure among women attending prevention of mother-to-child transmission in a state in South Nigeria
}

\author{
Adetumi A. Subulade ${ }^{1,2}$, Taofik A. Salami ${ }^{3}$, Gbolagade M. Adewuyi ${ }^{4}$ \\ ${ }^{1}$ Department of Public Health, Texila American University, Guyana, South America \\ ${ }^{2}$ Department of HIV Care, Federal Medical Centre, Owo, Ondo State, Nigeria \\ ${ }^{3}$ Department of Internal Medicine, Irrua Specialist Teaching Hospital, Irrua, Edo State, Nigeria \\ ${ }^{4}$ Department of Microbiology and Infectious Diseases, Irrua Specialist Teaching Hospital, Irrua, Edo State, Nigeria
}

\begin{abstract}
Introduction: About 50\% of people living with human immunodeficiency virus (HIV)/acquired immune deficiency syndrome (AIDS) (PLWHA) and in couple relationships have HIV-negative partners, and some of them have not disclosed their status to their sexual partners. As a result of this, new infections occur in sero-discordant relationships. Disclosure is important in couple's relationships. It promotes HIV testing of the partner, encourages HIV risk reduction practices, increases opportunity for social support and ultimately, facilitate long-term plans to ensure HIV prevention and management. The aim of the study is to assess factors in couples' relationship that determine the disclosure of HIV status for HIV pregnant women to their sexual partners.

Material and methods: This is a descriptive, cross sectional study among HIV-positive women accessing prevention of mother-to-child transmission (PMTCT) services in South state in Nigeria over a 3-month period. Data was collated with self-administered structured questionnaires and analyzed using SPSS 21.

Results: A total of $255 \mathrm{HIV}$-positive women recruited from PMTCT clinics participated in this study, of which $74.5 \%$ had disclosed their status to their sexual partners. Logistic regression should have significant relationship for HIV disclosure promotion in duration of marriage (OR = 7.0; CI: 1.3-38.5), knowledge of partner status $(\mathrm{OR}=14.3$; $\mathrm{CI}$ : 1.2-170.5), partner status and belief in the partners' support if disclosed (OR = 5.8; CI: 2.4-14.2).

Conclusions: This study shows that there are factors in HIV-infected couples' relationships that promote HIV disclosure to partners. These factors include duration of marriage, belief that partners will support following disclosure, and knowledge of partners' HIV status irrespective of sero-discordance. These factors should be considered in couples' counseling in order to encourage HIV disclosure.
\end{abstract}

HIV AIDS Rev $2018 ; 17,4: 283-287$ DOI: https://doi.org/10.5114/hivar.2018.80261

Key words: HIV, partner, couples, disclosure, PMTCT.

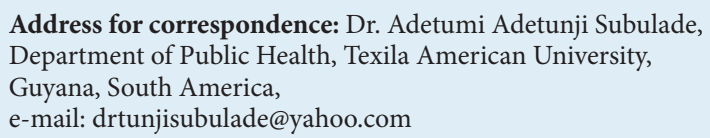

Address for correspondence: Dr. Adetumi Adetunji Subulade, Department of Public Health, Texila American University, Guyana, South America,

e-mail: drtunjisubulade@yahoo.com 


\section{Introduction}

About $50 \%$ of people living with human immunodeficiency virus (HIV)/acquired immune deficiency syndrome (AIDS) (PLWHA) in many couple relationships have HIV - negative partners [1]. Some of the HIV-positive individuals have not disclosed their status to their sexual partners and as a result, new infections occur in HIV sero-discordant relationships [2].

Disclosure is important in couples' relationship, in which one of the partners has tested positive for HIV. This has been shown to promote the HIV testing of the other partner in the relationship, encourages HIV risk reduction practices, increases opportunity for social support and ultimately, facilitate long-term plans to ensure HIV prevention and management. There are conditions in relationships that can determine if the infected partner will disclose the status to the sexual partner. This will as well determine adherence to HIV care and support programs. Most studies widely reported factors that hinder HIV disclosure as fear of stigmatization and rejection [3, 4], and few studies mentioned promoting factors, which included marital status and education level. Considering the importance of disclosure and recommendation for further studies on more factors that can enhance the process among the couples, there is a need to assess certain factors in couples' relationship that can contribute to disclosure [5].

This study aimed at assessing factors in couples' relationship that determine the disclosure of HIV status for HIV pregnant women to their sexual partners.

\section{Material and methods}

\section{Study setting}

This study was conducted in 36 health care facilities that offer prevention services of mother-to-child transmission of HIV (PMTCT) across the 18 local government areas (LGAs) of Edo state, Nigeria. Edo state is in the South of geopolitical zone of Nigeria, with 18 local governments in three senatorial districts: Edo North, Edo South, and Edo Central. The state has an estimated population of $3,218,332$ people, made up of $1,640,461$ males and $1,577,871$ females, and occupies a total land mass of $19,308.93 \mathrm{~km}^{2}$ [1]. There are 3 levels of health care providing facilities in the state: the tertiary specialized health facilities, the secondary health facilities, and the primary health care facilities. PMTCT services are offered in 1 tertiary specialized health facilities, 17 secondary health facilities, and 18 primary health care facilities [6] from where data was collected. Patients attend these different levels of health facilities based on their educational background, financial affordability, and ease of accessibility $[7,8]$, which could confound the outcome of this study. To avoid bias that might arise, stratified sampling technique was first used, in which the study participants were divided into 3 levels of health care facilities, and data were collected by convenience sampling technique from all HIV-positive women that attended PMTCT clinic from January to March 2016.

\section{Study population and study design}

The study population included HIV-positive women accessing PMTCT services in the selected health care facilities who gave written consent. Illiterates that were willing to participate had the consent well explained by volunteers who signed as witnesses. Exclusion criteria included HIV-negative women accessing care at the antenatal clinics. The sample size was calculated using the Kish Leslie formula for descriptive studies, with sample size $N$ generated as $N=\mathrm{pqz}^{2} / \mathrm{d}^{2}$. In the review of 25 published papers from January 1990 to December 2001 in sub-Saharan Africa by WHO, the least rate of HIV disclosure to sexual partners in the developing world was $16 \%$, which was used in this study as a prevalence rate, so as to have the estimated minimum size for an appropriate study $[9,10]$. Then, the sample size with $10 \%$ non-response rate made the estimated sample size to be 227 .

Cross-sectional, descriptive study design was used and data was collected from the respondents with the use of self-administered structured questionnaires. The questionnaire includes demographic variables, partner characteristics, partnership, disclosure status, disclosure barriers, partner's status, partner's reaction, and counseling types. The questionnaire was adapted from WHO review of different literatures $[9,11]$, and local settings of the study participants were put into consideration. The questionnaires were self-administered by the literate participants and the illiterates were guided in an interview session by recruited volunteers. To reduce interviewers bias, the volunteers were well trained with clearly structured questionnaires and the literate participants filled the questionnaires with little or no intervention from the interviewer, except for the illiterates.

\section{Data analysis}

The collated data was analyzed using SPSS software, version 21. Exploratory analysis was run to check for missing values and outliers and descriptive analysis was run for frequencies. To adjust for confounding and to determine whether the factors were independently associated with the disclosure of HIV results, logistic regression was conducted with the significance level of $p$-value less than 0.05 .

The study was approved by the research and ethics committee of the tertiary hospital, Irrua Specialist Teaching Hospital (ISTH) and the Edo state Hospital management board ethical committee. Formal letters of permissions were obtained from the institutions and written consent was obtained from all participants of the study. The right of the participants to withdraw from the interview or not to participate was assured throughout the questionnaire administration period. 


\section{Results}

\section{Disclosure rate}

Two hundred and fifty-five HIV-positive women participated in the study and most of the participants (33.7\%) were within the age range 26 to 30 years, and the highest level of education for majority (40.4\%) was a secondary school. $45 \%$ were self-employed, $81.2 \%$ were Christians, and $93.7 \%$ were married. Out of the 255 study participants, 190 (74.5\%) have disclosed their HIV status to sexual partners (Table 1).

\section{Response to disclosure}

Out of the 190 participants that disclosed their status to sexual partners, $89.5 \%$ acquired supportive responses, $7.3 \%$ responded that their partners were indifferent to the disclosure, while $2.1 \%$ were abusive and $1.1 \%$ were violent. One hundred and eighty-two (71.4\%) participants knew their sexual partners' HIV results, $58 \%$ of who responded that the partners have negative HIV status (sero-discordance). $6.3 \%$ of participants were not married and $74.5 \%$ of married were in monogamous marriage setting. $83.5 \%$ of participants responded that they believed their partners would support them if they disclosed their status (Table 2).

\section{Logistic regression of factors associated with disclosure}

Logistic regression was performed to assess the impact of factors in couples' relationships on the likelihood of disclosure HIV status of women accessing PMTCT services. The full model containing all predictors was statistically significant to appropriately fit the test, $\chi^{2}(\mathrm{df}=5$; $N=255)=135.8, p<0.001$, indicating the model was able to distinguish between respondents who disclosed and those who did not disclose their HIV status to their partners. The model correctly classified $88.2 \%$ of cases and as shown in Table 3; four of the independent variables made statistically significant contribution to the model (duration of marriage, knowledge of partner status, partner status, and belief in the partners' support if disclosed). The strongest predictor of HIV disclosure among the participants was status of sexual partner with odd ratio of 14.36 indicating that respondents who has partners with known HIV status either negative or positive were 14 times more likely to disclose their HIV status to their partner. In the same manner was duration of marriage, with odds ratio of 7 and the respondents who believed that they would receive support from their partners with odds ratio of 5.8. On the other hand, other factors that were not significant included marital status, number of wives, and educational level of the respondents.

\section{Discussion}

This study aimed at assessing factors in HIV-infected couples that determine HIV disclosure of the infected
Table 1. Socio-demographic characteristics of the study participants, Edo State, Nigeria

\begin{tabular}{|c|c|c|}
\hline Factor & Frequency & Percentage (\%) \\
\hline \multicolumn{3}{|l|}{ Age of respondents (years) } \\
\hline $16-20$ & 6 & 2.4 \\
\hline $21-25$ & 41 & 16.1 \\
\hline $26-30$ & 86 & 33.7 \\
\hline $31-35$ & 53 & 20.8 \\
\hline $36-40$ & 59 & 23.1 \\
\hline $41-45$ & 10 & 3.9 \\
\hline \multicolumn{3}{|l|}{ Level of education } \\
\hline Primary & 91 & 35.7 \\
\hline Secondary & 103 & 40.4 \\
\hline Technical & 12 & 4.7 \\
\hline Graduate & 32 & 12.5 \\
\hline Postgraduate & 17 & 6.7 \\
\hline \multicolumn{3}{|l|}{ Occupation of respondents } \\
\hline Self-employed & 115 & 45.1 \\
\hline Civil servant & 16 & 6.3 \\
\hline Private establishment & 18 & 7.1 \\
\hline Trader & 105 & 41.2 \\
\hline No response & 1 & 0.4 \\
\hline \multicolumn{3}{|l|}{ Religion } \\
\hline Christianity & 207 & 81.2 \\
\hline Islam & 43 & 16.9 \\
\hline Others & 5 & 2 \\
\hline \multicolumn{3}{|l|}{ Marital status } \\
\hline Married & 239 & 93.7 \\
\hline Single & 16 & 6.3 \\
\hline Total & 255 & 100 \\
\hline
\end{tabular}

women to their sexual partners. $74.5 \%$ of the participants in the study had disclosed their status, which is close to $81 \%$ reported by Makin et al. in his South Africa study among women accessing PMTCT services [12]. It is similar to the disclosure rate of $72.6 \%$ in a study by King et al. in Uganda [13], but higher than $62 \%$ in Niger Delta region of Nigeria by Ebueny et al., which was conducted among infected adults in a single tertiary institution that could have accounted for the difference [14].

Those that have been married for 2 years and above disclosed their HIV status better to their sexual partners, which was also reported by Kiula et al. in a study in Tanzania among HIV-positive women accessing PMTCT care [15]. HIV-positive women in the study who had knowledge of their partners HIV status were encouraged to disclose their HIV status. Knowing the status of partners seemed to give confidence to the women and enhanced disclosure despite the $58 \%$ sero-discordance rate among the partici- 
Table 2. HIV disclosure determinant factors

\begin{tabular}{l|c|c|c}
\hline Variables & Responses & Frequency & Percentage \\
\hline \multirow{2}{*}{ HIV status disclosure } & Yes & 190 & 74.5 \\
\hline \multirow{4}{*}{ Status of partners } & No & 65 & 25.5 \\
\cline { 2 - 4 } & Positive & 76 & 29.8 \\
\hline & Negative & 106 & 41.6 \\
\cline { 2 - 4 } & Unknown & 18 & 28.6 \\
\hline \multirow{3}{*}{ Duration of marriage } & Less than 2 years & 99 & 3.1 \\
\cline { 2 - 4 } & Between 2 to 5 years & 122 & 38.8 \\
\cline { 2 - 4 } & Above 5 years & 16 & 47.8 \\
\cline { 2 - 4 } Number of wives & Not married & 61 & 2.3 \\
\hline \multirow{2}{*}{ Belief in partners support if status is disclosed } & Polygamous & 178 & 74.5 \\
\cline { 2 - 4 } & Monogamous & 213 & 83.5 \\
\cline { 2 - 4 } & Yes & 35 & 13.8 \\
\hline
\end{tabular}

Sero-discordance rate is 58\%; reactions of partners to disclosure - $89.5 \%$ supportive

Table 3. Logistic regression for predictors of HIV disclosure to partners among women attending prevention of motherto-child transmission (PMTCT) services

\begin{tabular}{l|c|c|c}
\hline Variables in model & $\begin{array}{c}\text { Odds } \\
\text { ratio }\end{array}$ & $\mathbf{9 5 \%} \mathrm{Cl}$ & $\boldsymbol{p}$-value \\
\hline Marital status & 11.08 & $0.33-366$ & 0.178 \\
\hline Duration of marriage & 7 & $1.3-38.5$ & $<0.05$ \\
\hline $\begin{array}{l}\text { Number of wives by } \\
\text { partner }\end{array}$ & 0.891 & $0.324-2.45$ & 0.822 \\
\hline $\begin{array}{l}\text { Status of sexual } \\
\text { partner }\end{array}$ & 14.36 & $1.21-170.6$ & $<0.05$ \\
\hline $\begin{array}{l}\text { Belief in partners } \\
\text { support if status is } \\
\text { disclosed }\end{array}$ & 5.8 & $2.4-14.2$ & $<0.0001$ \\
\hline Educational level & 0.28 & $0.014-5.53$ & 0.403 \\
\hline
\end{tabular}

$\mathrm{Cl}$ - confidence interval, percentage accuracy in classification $(P A C)-88.2 \%$; omnibus test of model co-efficient (goodness of fit) $-\chi^{2}(d f=5, N=255)=135.8$, $p<0.001$; Hosmer and Lemeshow test -0.898 , sensitivity $-90 \%$, specificity $-83.1 \%$

pants. This same occurrence was reported by Batte et al. in his study among women attending antenatal clinic in Ugan$\mathrm{da}$, where he showed that knowledge of HIV status of partners promotes disclosure irrespective zof the level of status sero-discordance [16]. WHO reported this to be a good factor in couples' counseling for HIV disclosure [11, 17]. Majority of those who have disclosed their status believed before that disclosure would make their partners supportive, which was very significant in this study. Nevertheless, the scope of the study did not identify what influenced this belief, it could possibly have been due to counseling received at the facilities on the benefits of disclosure; however, this supposition requires further study.
Makin et al. in a study among HIV-positive women receiving PMTCT service in South Africa reported that women who are married and are educated are more likely to disclose their status to their partners $[12,16,18]$; this study did not show any significance in the relationship. A study by Burmen et al. also reported insignificant relationship in the two variables in his study in adult HIV-infected individuals in Kenya [19]; further study with bigger sample size is required. The family style of more than one wife did not show any significant relationship with disclosure of status to the sexual partners.

$89.5 \%$ of those that disclosed acquired good support from their sexual partners, which was further supported by Ogoina et al., who reported that $72.4 \%$ of participants in his study received initial support from partners following disclosure, which increased to $89.5 \%$ at follow-up [20]. The studies reviewed in the discussion, which are not among HIV-positive women could have given a different interpretation because of the study population.

\section{Limitations}

Disclosure status and partner's HIV status was acquired by self-reporting and was not verified by partner's interview or HIV testing. This study was applied only to HIV-positive women over three months. Men involvement and prolonging study time could possibly allow to capture the responses that would further represent the true factors that promote HIV disclosure.

\section{Conclusion and recommendation}

This study showed that there are factors in the relationship between couples that promote HIV disclosure among 
sexual partners. These factors include duration of marriage, belief that partners will support following disclosure, and knowledge of partners' HIV status irrespective of sero-discordance. These factors should be well considered and reinforced in couples' counseling, which can promote HIV disclosure; however, very few studies reported factors promoting disclosure among HIV-positive women accessing PMTCT services, so there is a need for further studies investigating these aspects.

\section{Conflict of interest}

The authors declare no potential conflicts of interest with respect to the research, authorship, and/or publication of this article.

\section{References}

1. Amoran OE. Predictors of disclosure of sero-status to sexual partners among people living with HIV/AIDS in Ogun state, Nigeria. Niger J Clin Pract 2012; 15: 385-390.

2. Skogmar S, Shakely D, Lans M, et al. Effect of antiretroviral treatment and counseling on disclosure of HIV serostatus in Johannesburg, South Africa. AIDS Care 2006; 18: 725-730.

3. Titilope AA, Adediran A, Umeh C, et al. Psychosocial impact of disclosure of HIV serostatus min heterosexual relationship at the Lagos University teaching hospital, Nigeria. Niger Med J 2011; 52: 55-59.

4. Almayehu M, Aregay A, Kalayu A, Yebyo H. HIV disclosure to sexual partner and associated factors among women attending ART clinic at Mekelle hospital, Northern Ethiopia. BMC Public Health 2014; 14: 746.

5. Deribe K, Woldemichael K, Wondafrash M, et al. Disclosure experience and associated factors among HIV positive men and women clinical service users in southwest Ethiopia. BMC Public Health 2008; 8: 18.

6. Edo State Ministry of Health. Edo State Government strategic health development plan 2010-2015. Available at: www.mamaye. org.ng/.../Edo\%20SSHDP\%20revised\%2005.0.11_0.pdf.

7. Sagay A, Musa J, Ekwempu C, et al. Partner disclosure of HIV status among HIV positive mothers in Northern Nigeria. Afr J Med Med Sci 2006; 35 (Suppl): 119-123.

8. Federal Ministry of Health [FMOH]. Integrated national guidelines for HIV prevention treatment and care. National AIDS/STIs Control Program, Nigeria. Available at: www.who.int/hiv/pub/ guidelines/nigeria_art.pdf.

9. World Health Organization. Gender dimensions of HIV status disclosure to sexual partners: rates, barriers and outcomes. Department of Gender and Women Health. 2004. Available at: http://apps. who.int/iris/bitstream/10665/42717/1/9241590734.pdf.

10. World Health Organization. Preparing a research project proposal: guidelines and forms', UNDP/UNFPA/WHO/World Bank Special Program of Research, Development and Research Training in $\mathrm{Hu}$ man Reproduction. 2003. $4^{\text {th }}$ ed. Available at: http://www.gfmer.ch/ SRH-Course-2011/research-methodology/pdf/WHO-proposalguidelines-forms-2003.pdf.

11. World Health Organization. Guidance on Couples HIV testing and counseling (CHTC), WHO HIV/AIDS Programme. 2012. Available at: http://www.who.int/hiv/pub/guidelines/9789241501972/en/.

12. Makin JD, Forsyth WC, Visser MJ, et al. Factors affecting disclosure in south African HIV-positive pregnant women. AIDS Patient Care STDS 2008; 22: 907-916.

13. King R, Katuntu D, Lifshay J, et al. Processes and outcomes of HIV serostatus disclosure to sexual partners among people living with HIV in Uganda. AIDS Behav 2008; 12: 232-243.
14. Ebuenyi I, Ogoina D, Ikuabe P, et al. Prevalence pattern and determinants of disclosure of HIV status in an anti-retroviral therapy clinic in the Niger Delta region of Nigeria. Afr J Infect Dis 2014; 8: 27-30.

15. Kiula ES, Damian DJ, Msuya SE. Predictors of HIV serostatus disclosure to partners among HIV-positive pregnant women in Morogoro, Tanzania. BMC Public Health 2013; 13: 433.

16. Batte A, Katahoire R, Chimoyi A, et al. Disclosure of HIV test results by women to their partners following antenatal HIV testing: a population-based cross-sectional survey among slum dwellers in Kampala Uganda. BMC Public Health 2015; 15: 63.

17. World Health Organization. Prevention of mother to child transmission: situation and trends, Global Health Observatory data. 2013. Available at: http://www.who.int/gho/hiv/epidemic_response/ PMTCT_text/en/.

18. Walcott M, Hatcher A, Kwena Z, Turan J. Facilitating HIV status disclosure for pregnant women and partners in rural Kenya: a qualitative study. BMC Public Health 2013; 13: 1115.

19. Burmen B, Obunga J, Mutai K. Disclosure status and disclosure intentions among HIV positive persons in rural western Kenya, 2011-2012. J Cogent Med 2017; 4: 1291096.

20. Ogoina D, Ikuale P, Ebuenyi I, et al. Types and predictors of partner reactions to HIV status disclosure among HIV-infected adult Nigerians in a tertiary hospital in the Niger Delta. Afr Health Sci 2015; 15: $10-18$. 